\title{
Understanding Binding of Cyano-Adamantyl Derivatives to Pillar[6]arene macrocycle from Density Functional theory.
}

Smita A. Bhadane, Dipali N. Lande and Shridhar P. Gejji*

Department of Chemistry, Savitribai Phule Pune University, 411 007, India

\section{Supporting Information}

Figure S1. (i) Destabilized conformer of (i) ACN@EtP[6] and (ii) AMCN@EtP[6] complex. Relative stabilization energies are given in $\mathrm{kJ} \mathrm{mol}^{-1}$ parentheses.

Figure S2. Comparison of vibrational spectra of EtP[6], AMCN and AMCN@EtP[6]]complex in different region i) $3300-2900 \mathrm{~cm}^{-1}$ and ii) $24400-2300 \mathrm{~cm}^{-1}$ iii) $1600-400$.

Table S1. $\quad{ }^{1} \mathrm{H}$ NMR chemical shifts in solvent (chloroform) in host, guest and their complexes. 
(i)
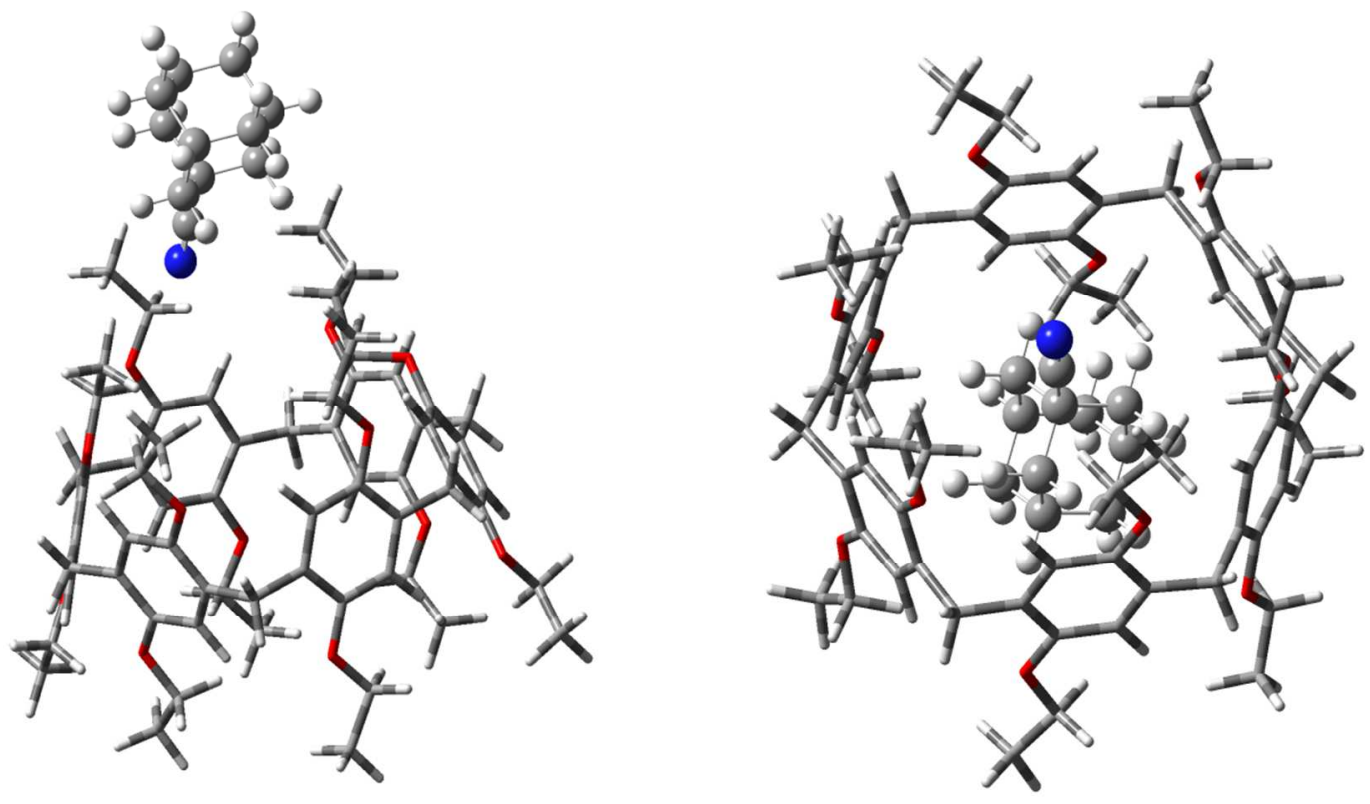

(ii)
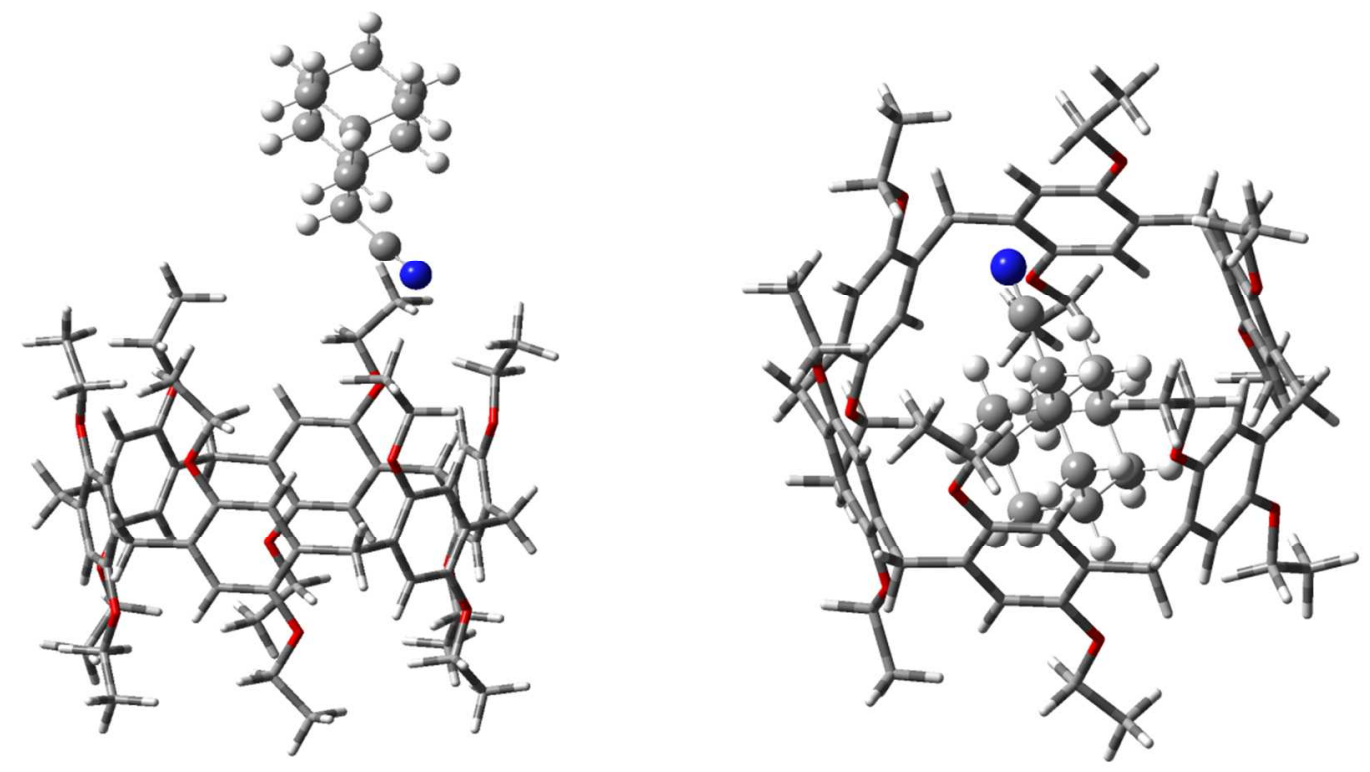

Figure S1 


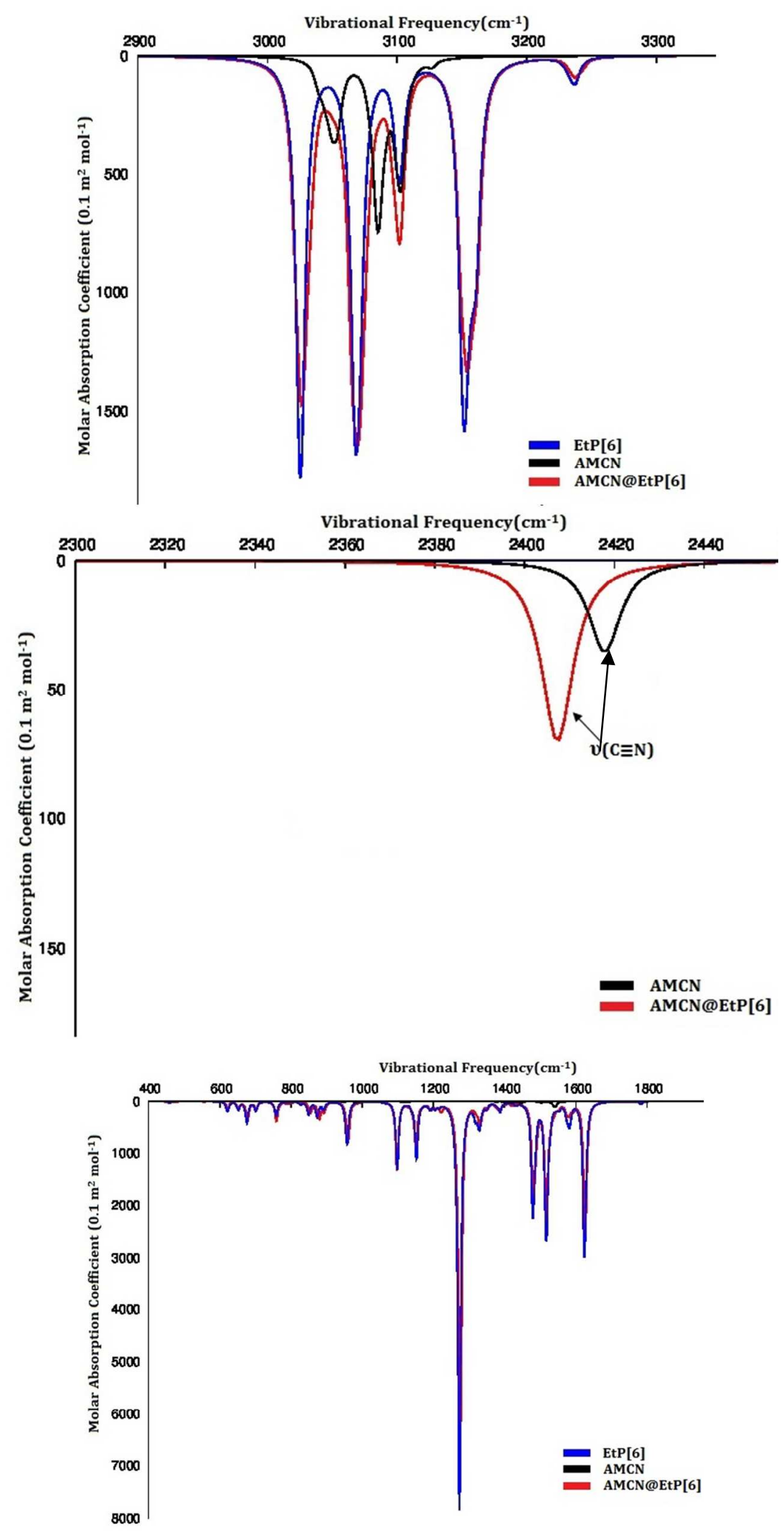

Figure S2 
Table S1. ${ }^{1} \mathrm{H}$ NMR chemical shifts in host, guest and their complexes using chloroform as a solvent at $\omega B 97 x / 6-311+G(d, p)$.

\begin{tabular}{lccccc}
\hline & EtP[6] & ACN & ACN@EtP[6] & AMCN & AMCN@EtP[6] \\
\hline Ha & 7.47 & & 7.81 & & 7.51 \\
Hb & 3.96 & & 3.47 & & 3.9 \\
Hc out & 3.94 & & 3.56 & & 3.99 \\
Hc in & 3.77 & & 3.02 & & 3.9 \\
Hd & 1.64 & & 0.87 & & 1.64 \\
H1 & & 1.93 & -2.48 & 1.56 & -2.72 \\
H2 & & 1.79 & -0.56 & 1.82 & 1.82 \\
H3 & & 1.70 & -0.63 & 1.65 & 0.57 \\
H4 & & & & 1.92 & 0.06 \\
\hline
\end{tabular}


